\title{
Von Recklinghausen's disease intra oral manifestation: A rare entity
}

\author{
Kundoor Vinay Kumar Reddy ${ }^{1}$, Kotya Naik Maloth ${ }^{2, *}$, Tejaswini Meesala ${ }^{3}$, Moni Thakur ${ }^{4}$ \\ ${ }^{\mathbf{1}}$ Professor and Head, ${ }^{\mathbf{2} 4}$ Assistant Professor, ${ }^{3}$ Post Graduate Student, ${ }^{\mathbf{1 - 3}}$ Dept. of Oral Medicine and Radiology, ${ }^{4}$ Dept. of Oral and \\ Maxillofacial Pathology, Mamata Dental College and Hospital, Khammam, Telangana, India \\ *Corresponding Author: \\ Email: dr.kotyanaik.maloth@gmail.com
}

\begin{abstract}
Neurofibromatosis (NF) is an autosomal-dominant disorder, characterized by neurocutaneous tumors arising within multiple organs, which the diagnosis is made based on clinical criteria proposed by National Institute of Health Consensus Development Conference. Neurofibromatosis type I (NF-1), also termed as von Recklinghausen's disease, is the most common type accounting $90 \%$ of the cases. We report a clinical case of NF-1 with oral manifestations in a 60 -year-old female patient.
\end{abstract}

Keywords: Glioma, Lisch nodules, Neurofibromatosis, Neurocutaneous tumors.

\section{Introduction}

A group of genetic diseases, which primarily affecting the neural tissue growth is termed as neurofibromatosis (NF). Based on the mutations on different genes it is classified into two types neurofibromatosis type 1 (NF-1) and neurofibromatosis type 2 (NF-2), having few common features. ${ }^{1,2} \mathrm{NF}-1$ is an autosomal dominant genetic disorder caused due to mutation of the NF1 gene on chromosome 17q11.,2,3 characterized by neurocutaneous disorders arising within multiple organs, involving the sheaths / peripheral nerves associated with hyperpigmentation. ${ }^{4}$

Friederich Daniel Von Recklinghausen a German pathologist was the first person to describe this entity in 1882 , so as a honor it is named as von Recklinghausen's disease..$^{5}$ It is the most common type accounting for about $90 \%$ of the cases, with a prevalence of one in 3000 births. ${ }^{1,6}$ Here, we report a case of neurofibromatosis type I with cutaneous and oral manifestations in a 60 year old female.

\section{Case Report}

A 60 years old female patient visited to the department with a chief complaint of swelling in the palate region, which was gradually increasing in size. On general physical examination multiple soft tissue nodules were present on entire body (neurofibroma) with hyperpigmention (Cafe-au-lait pigmentation) [Fig. 1]. The multiple soft tissue nodules were also seen on head and neck region, on hands, legs and trunk region [Fig. 2a, 2b, 2c and 2d]. Oral manifestation of neurofibroma on the hard palate [Fig. 3] is seen. Her systemic history was non-contributory and gives history of her offsprings with similar skin neurofibromas with cafe-au-lait pigmentations. Dental related problems were treated. Surgical excision of intraoral neurofibroma on the hard palate was done under local anesthesia and sent for histopathology, which revealed composed of Schwann cells, perineurial cells and noncapsulated endoneurial fibroblasts. Schwann cells are more predominant cellular type with wide nuclei and a wavy form of shape and sharp corners, suggestive of neurofibroma [Fig. 4].

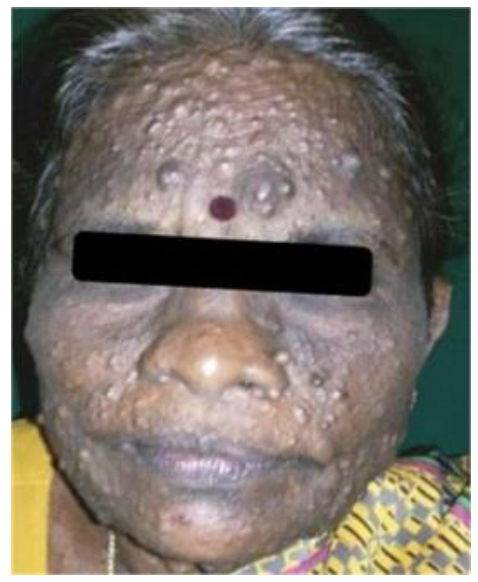

Fig. 1: Cutaneous fibromas on face with cafe-au-lait pigmentations
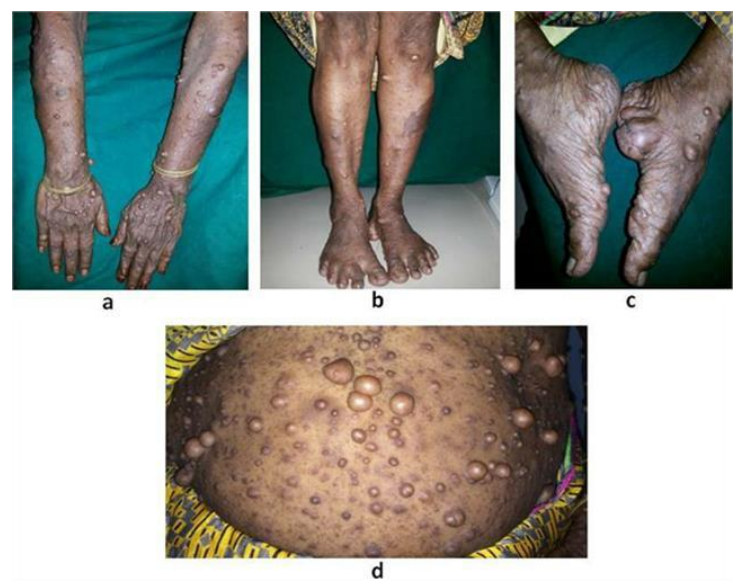

Fig. 2: Cutaneous fibromas on hands (a), legs (b, c) and trunk (d) 


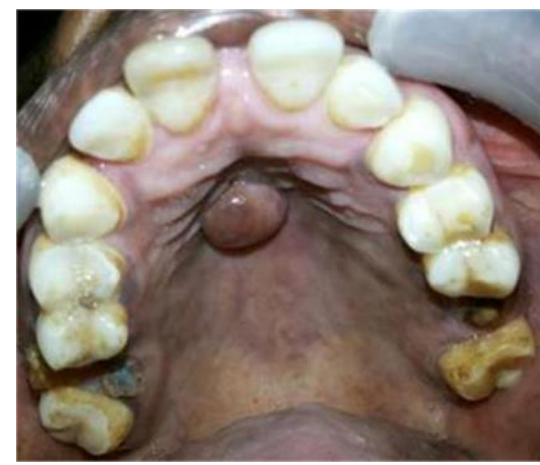

Fig. 3: Intra oral neurofibroma on the hard palate

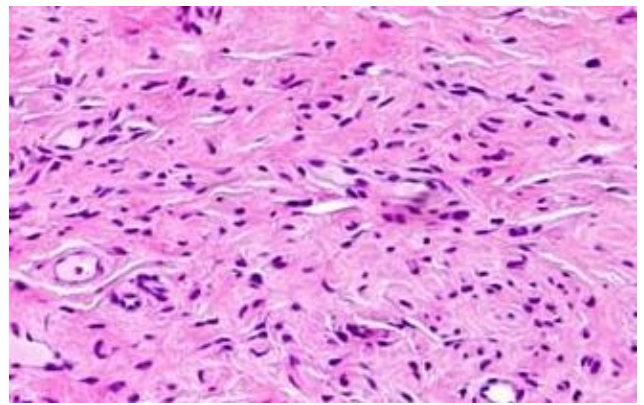

Fig. 4: Mixture of Schwann cells, perineurial cells and non-capsulated endoneurial fibroblasts

\section{Discussion}

Neurofibromatosis type I is an autosomal dominant inheritance disease, characterized by physical, neurological and ocular involvement, affecting approximately 1 in 3500 people. $^{7}$ In 1849 , Robert William Smith was the first person to describe the manifestations of neurofibromatosis, but existed since long time. Later, in 1882, Friedrich Daniel von Recklinghausen a German pathologist given the classic description of this entity described the diverse findings as a single entity, thus it is often referred as von Recklinghausen's disease. ${ }^{6,8}$

In 1987, National Institute of Health Consensus Development Conference was held, which proposed seven cardinal diagnostic criteria for NF1. ${ }^{9}$ Any two of the following seven criteria are met, a diagnosis of NF1 is made:

1. Two or more neurofibromas or one plexiform neurofibroma,

2. Freckling of the groin or the axilla,

3. Six or more cafe-au-lait pigmentation measuring $5 \mathrm{~mm}$ in pre-pubescent and $15 \mathrm{~mm}$ in postpubescent individuals,

4. Skeletal abnormalities such as sphenoid dysplasia or thinning of the cortex of the long bones,

5. Two or more Lisch nodules (hamartomas of the iris),

6. Optic glioma, or

7. A first-degree relative with NF1.

The present case reported with neurofibromas on entire body, on the palate with multiple cafe-au-lait pigmentations on the face and hands and axillary freckling.

Multiple neurofibromas along peripheral nerves and cafe-au-lait pigmentations are the common clinical manifestation of NF 1. Cutaneous neurofibromas most commonly occur on the trunk and limbs, which are soft, skin or pink colored tumors with sessile or domeshaped and sometimes pedenculated base. Other clinical manifestations include Lisch's nodules (melanocytic pigmented iris hamartomas) of eye and oral neurofibromas, which are rare. ${ }^{6}$ The present case reported is consistent with the literature.

Plexiform neurofibromas are poorly-circumscribed and locally invasive tumors affecting about $21 \%$ of the patients with NF-1, which spreads along the peripheral nerves. The fifth, ninth, and tenth cranial nerves are most commonly involved. ${ }^{1,2}$ About $40 \%$ of the patients with NF-1 also exhibit skeletal abnormalities. Various neurological disorders like hamartomas of the iris, neurinomas of the acoustic nerve, tumors of the central nervous system (gliomas, glioblastomas), macrocephalies, and mental retardation was noted in majority of cases with NF-1. ${ }^{2}$

Intraoral manifestations of neurofibroma were seen any part of the oral cavity, but most commonly seen on the tongue followed by hard or soft palate. ${ }^{10}$ Shapiro et al (1984) reported in his study that in $72 \%$ of NF1 patients having oral manifestations. ${ }^{11}$ D'Ambrosio et al (1988) performed a survey and found 66\% of NF1 patients had at least one intraoral manifestation and $58 \%$ lesions are manifested in the maxilla and mandible. ${ }^{12}$ In the present case neurofibroma located on hard palate.

Histolopathologically, neurofibromas are composed of Schwann cells which account for about 36 to $80 \%$ of the lesional cells, perineurial cells which account for about $0.7-31 \%$ of the cells and endoneurial fibroblasts, which are not capsulated. Schwann cells are more predominant cellular type with wide nuclei and a wavy form of shape and sharp corners. ${ }^{13}$

NF-1 systemically affecting multiple organs, which requires a treatment in multidisciplinary approach. No definite treatment is present for NF-1, rather the management must be toward preventive measures, and as well to control any complications. The potential rate for malignancy is rare (3-5\%), but these tumors may cause clinical problems like esthetic and functional abnormalities. Surgical management for these types of lesions is non-satisfactory, as the complete removal multiple lesions is very difficult. Surgical intervention is indicated only when the patient's function is impaired. ${ }^{14}$

\section{Conclusion}

The neurofibromatosis is a common an autosomal dominant disorder. So genetic consulting is necessary before marriage and before becoming pregnant. The case reported here is a rare entity of NF-1 with oral 
manifestations with high generalization of the skin lesion. Some of the cases affected systemically multiple organs leading to complications, due to this most of the dentists do not treat dental problems. In such cases, a thorough knowledge regarding the disease is required for proper diagnosis before management of the disease and it is our duty, as oral and maxillofacial medicine specialists, to manage the entity. The treatment of such kind of patient is surgical, seeking to achieve cosmetic improvement, and may be only palliative.

\section{References}

1. Ghalayani P, Saberi Z, Sardari F. Neurofibromatosis type I (von Recklinghausen's disease): A family case report and literature review. Dent Res J (Isfahan). 2012;9:483-8.

2. García-de Marcos JA, Dean-Ferrer A, AlamillosGranados F, Ruiz- Masera JJ, García-de Marcos MJ, Vidal-Jiménez A, et al. Gingival neurofibroma in a neurofibromatosis type 1 patient. Med Oral Patol Oral Cir Bucal. 2007;12:E287-91.

3. Viskochil D, Buchberg AM, Xu G, Cawthon RM, Stevens J, Wolff RK, et al. Deletions and a translocation interrupt a cloned gene at the neurofibromatosis type 1 locus. Cell. 1990;62:187-192.

4. Kim BK, Choi YS, Gwoo S, Park YH, Yang SI, Kim JH. Neurofibromatosis type 1 associated with papillary thyroid carcinoma incidentally detected by thyroid ultrasonography: a case report. Journal of Medical Case Reports. 2012;6:179.

5. Hillier JC, Moskovic E. The soft tissue manifestations of neurofibromatosis type 1. Clin Radiol. 2005;60:960-7.

6. Dimitrova V, Yordanova I, Pavlova V, Valtchev V, Gospodinov D, Parashkevova B, et al. A Case of Neurofibromatosis Type 1. Journal of IMAB. 2008;14:637.
7. Moraes FS, de Moura Santos WE, Salomão GH. Neurofibromatosis type I. Rev Bras Oftalmol. 2013;72(2):128-31.

8. von Recklinghausen FD: Ueber die multiplen Fibrome der Haut und ihre Beziehung zu den multiplen Neuromen. Berlin, Hirschwald. 1882.

9. National institutes of health consensus development conference: Neurofibromatosis conference statement. Arch Neurol. 1988;45:575-8.

10. Bongiorno MR, Pistone G, Aricò M. Manifestations of the tongue in Neurofibromatosis type 1. Oral Dis. 2006;12:125-9.

11. Shapiro SD, Abramovitch K, van Dis ML, Skoczylas LJ, Langlais RP, Jorgenson RJ, et al. Neurofibromatosis: Oral and radiographic manifestations. Oral Surg Oral Med Oral Pathol. 1984;58:493-8.

12. D' Ambrosio JA, Langlais RP, Young RS. Jaw and skull changes in neurofibromatosis. Oral Surg Oral Med Oral Pathol. 1988;66:391-6.

13. Holtzman L. Radiographic manifestation and treatment consideration in a case of multiple neurofibromatosis. $J$ Endod. 1998;24:442-3.

14. Maceri DR, Saxon KG. Neurofibromatosis of the head and neck. Head Neck Surg. 1984;6:842-50.

How to cite this article: Reddy KVK, Maloth KN, Meesala T, Thakur M. Von Recklinghausen's disease intra oral manifestation: A rare entity. Ind $\mathbf{J}$ Clin Exp Dermatol. 2018;4(3):263-265. 